\title{
Thymic epithelial cell development and differentiation: cellular and molecular regulation
}

\author{
Lina Sun, Haiying Luo, Hongran Li, Yong Zhao \\ State Key Laboratory of Biomembrane and Membrane Biotechnology, Institute of Zoology, Chinese Academy of Sciences, Beijing \\ 100101, China \\ $\triangle$ Correspondence: zhaoy@ioz.ac.cn \\ Received February 14, 2013 Accepted March 11, 2013
}

\begin{abstract}
Thymic epithelial cells (TECs) are one of the most important components in thymic microenvironment supporting thymocyte development and maturation. TECs, composed of cortical and medullary TECs, are derived from a common bipotent progenitor, mediating thymocyte positive and negative selections. Multiple levels of signals including intracellular signaling networks and cell-cell interaction are required for TEC development and differentiation. Transcription factors Foxn1 and autoimmune regulator (Aire) are powerful regulators promoting TEC development and differentiation. Crosstalks with thymocytes and other stromal cells for extrinsic signals like RANKL, CD40L, lymphotoxin, fibroblast growth factor (FGF) and Wnt are also definitely required to establish a functional thymic microenvironment. In this review, we will summarize our current understanding about TEC development and differentiation, and its underlying multiple signal pathways.
\end{abstract}

KEYWORDS thymus, thymic epithelial cells, Aire, Foxn1, TNFR, NF-KB, FGFs

\section{INTRODUCTION}

As a primary lymphoid organ, thymus is the site that $\mathrm{T}$ cell development and maturation take place. Thymic epithelial cells (TECs) and thymocytes are the most important components in thymic microenvironment in which TECs form a 3-dimentional network filled with thymocytes in different developmental stages. Besides, macrophages, dendritic cells (DCs), fibroblasts and mesenchyme cells also present in thymus. Based on the location in thymus, TECs can be divided into two major subsets: cortical (cTEC) and medullary TECs (mTEC) located in the outer cortex and the inner medulla area, respectively. Thymocytes develop and mature while migrating through thymic cortex and medulla by interacting with TECs. With no doubt, TECs are the key part in thymic environment to shape T cell development. Thymocytes that succeed in positive selection mediated mainly by cTECs and negative selection mainly mediated by mTECs are mature to functional $T$ cells with self$\mathrm{MHC}$ recognition and tolerant to self antigens (Anderson and Takahama, 2012; Guerder et al., 2012). The knowledge about TEC development, differentiation and the underlying mechanisms will significantly help us to better understand the thymic microenvironment essential for the thymic lymphopoiesis. Though a wealth of information on TECs has become available during the past decades, the precise developmental pathways and molecular mechanisms regulating TEC maturation remain poorly defined. This review will focus on recent findings related to the development and molecular regulation of TECs.

\section{THYMUS ORGANOGENESIS AND TEC DEVELOPMENT}

On approximately day 9 of embryonic development (E9) in mice, the thymus rudiment arises from the endoderm of the third pharyngeal pouch. The thymus rudiment contains bipotent precursors that could develop into both cTECs and mTECs (Bleul et al., 2006; Rossi et al., 2006; Zhang et al., 2007). cTECs and mTECs are remarkably different in the respects of cytokeratin expression, in which most mTECs express cytokeratin 5 (K5) and K14 but cTECs express K8 and K18 (Alexandropoulos and Danzl, 2012). TECs that express both K5 and $\mathrm{K} 8\left(\mathrm{~K}^{+} \mathrm{K}^{+}\right)$are mainly located at the cortico-medullary 
junction. They are part of CTECs or the immature progenitors for both mTECs and cTECs. Furthermore, mTECs are positive for the expression of Ulex europaeus agglutinin-1 (UEA-1) on cell surface, but not Ly51 (UEA-1 $1^{+}$Ly $51^{-}$), while cTECs are UEA $-1^{-}$Ly $51^{+}$. So we can roughly distinguish mTECs from cTECs in immunofluorescence and flow cytometry assays.

The exact development and differentiation process of mTECs and cTECs remains elusive. It is well accepted that mTECs and cTECs share a common bipotent progenitor (TEPC) during thymus organogenesis (Rossi et al., 2006), and this progenitor pool lasts for a very long time after birth to support continuous TEC generation and homeostasis (Bleul et al., 2006). Though little is known about the characterization of these TEPCs, the size of the TEC progenitor pool significantly controls the number of mature TECs and limits their recovery (Jenkinson et al., 2008). Once the progenitor pool was ruined during embryogenesis, postnatal TECs could not be fully recovered. This may due to inability of self-renewal for progenitors (Corbeaux et al., 2010). Further results demonstrated that the individual progenitors for CTECs and mTECs might exist (Rodewald et al., 2001; Hamazaki et al., 2007). The mTECs highly expressed the tight-junction protein claudin-3 and claudin-4 (UEA- $1^{+} \mathrm{Cld} 3,4^{\mathrm{hi}}$ ) represent the progenitors specifically for Aire ${ }^{+}$mTECs (Hamazaki et al., 2007). Otherwise, the progenitors for cTECs emerge on E15, and are phenotypically characterized as $\mathrm{EpCAM}^{+} \mathrm{CD} 205^{+} \mathrm{CD}_{40}{ }^{-}$(Shakib et al., 2009).

Many studies about TEC development focused on mTECs. Thus, comparing to CTECs, the development pathways of mTECs are much better defined. Generally, the development of mTECs is divided into 3 stages: immature mTEC which express UEA-1 but lower expression of $\mathrm{MHCll}$ and costimulatory molecules CD80/CD86. As mTECs develop further, MHCII and CD80/86 are up-regulated concomitantly. In the middle mature stage of mTECs, they still do not express the autoimmune regulator (Aire) and functionally immature. The full mature mTECs are phenotypically characterized as high expression of $\mathrm{MHCll}$, CD80/86 and Aire (UEA- $1^{+} \mathrm{MHCII}^{\mathrm{hi}} \mathrm{CD} 80 / 86^{\mathrm{hi}}$ Aire ${ }^{+}$) as well as up-regulation of Aire-dependent and Aire-independent tissuerestricted antigens (TRAs) participating in thymocyte negative selection (Alexandropoulos and Danzl, 2012).

There are two models explaining the mTEC development, which are "terminal differentiation model" and "progressive restriction model" based on the Aire expression and function (Gillard and Farr, 2005). The "terminal differentiation model" postulates that the mature $\mathrm{MHCI}{ }^{\mathrm{hi}} \mathrm{CD} 80^{\mathrm{hi}} \mathrm{Aire}^{+}$mTECs develop from the immature $\mathrm{MHCll}{ }^{\text {low }} \mathrm{CD} 80^{\text {low }} \mathrm{Aire}^{-}$subsets (Gray et al., 2007). Correlating with $\mathrm{MHCll}$ and $\mathrm{CD} 80$ upregulation, the TRAs expression are also increased and with a promiscuous and stochastic manner (Gabler et al., 2007). In contrast, the "progressive restriction model" claims that Aire and TRAs expression are properties of immature mTECs. MTEC differentiation is driven by Aire. Therefore, the expression of TRAs is restricted with cell lineage specificity. Obviously, the key distinguishing features of the two models is the function that Aire plays in MTEC development and differentiation. The first view- point indicates that the Aire is a marker for mature mTECs, while the secondary one emphasizes that Aire expressed in immature mTECs regulates mTEC development and TRAs' expression. By examination of the proliferation and turnover of Aire $^{+}$or Aire ${ }^{-}$mTECs through the in vivo BrdU incorporation assays, Daniel Gray et al presumed that Aire $^{+}$mTECs were almost postmitotic and derived from Aire ${ }^{-}$precursors with higher turnover. Aire did not have impact on the cell division of mTECs. These results strongly favor the "terminal differentiation model" (Gray et al., 2007). Additional evidence comes from comparison of the expression profile of the casein gene locus in mTECs and mammary gland epithelial cells by single cell PCR. Unlike highly correlated expression pattern in mammary gland epithelial cells, casein expression in mTECs was promiscuous (Derbinski et al., 2008). However, some data also seem to favor the "progressive restriction model". Based on a previous demonstration that some thymic epithelium expressed lung-associated genes resemble an ultrastructural feature of respiratory epithelium, it was proposed that TEC development had cell lineage specificity (Farr et al., 2002). The TRAs expression in TECs was regulated at multiple levels including Aire-dependent and -independent manner, and even epigenetic regulation (Derbinski et al., 2005). One strong evidence is that Aire ${ }^{-/}$thymus have altered medulla structure, mTECs composition and abnormal TRAs expression with severe autoimmune disease symptom (Ramsey et al., 2002; Gillard et al., 2007), supporting the "progressive model".

A series of reports shed lights on the end-stage terminal differentiation of mTECs. At the beginning, the $\mathrm{MHCII}^{\text {hi }}$ CD $80^{\text {hi }}$ Aire $^{+}$mTECs subset has been generally considered to be the postmitotic end-stage of mTECs which they will be removed by apoptosis. However, accumulating evidences have shown that the mTECs might continually develop beyond the Aire $^{+}$stages. First, the Hassall's corpuscles (HCs) containing terminally differentiated mTECs positive for terminally differentiated markers in epidermis are present in the thymic medulla (Hale and Markert, 2004). Because Aire $^{-/-}$mice have no HCs (Yano et al., 2008), and the presence of HCs follows the Aire ${ }^{+}$mTECs during ontogeny (White et al., 2010), By using cell fate tracing method, Nishikawa and his colleagues demonstrated that Aire ${ }^{+} \mathrm{CD} 80 \mathrm{MHCll}$ mTECs developed to Aire ${ }^{-} \mathrm{CD} 80^{\text {int }} \mathrm{MHCll}^{\text {low }}$ end-stage (Nishikawa et al., 2009). A recent paper reported that a single mTEC have 2- to 3-weeks' life-cycle, during this time, Aire is expressed only once within possible maximal 1-2 days. The loss of Aire expression is accompanied by down-regulation of MHCII, CD80 and TRAs. In the final developmental stage, mTECs lose their nuclei to become HCs (Wang et al., 2012). So in general, the expression of Aire, CD80 and MHCII undergoes a dynamic changes from low to high and then to low expression. The end-stage of mTECs express involucrin which is a marker of terminally differentiated epithelium. During ontogeny, the presence of involucrin ${ }^{+}$TECs followed the Aire ${ }^{+}$TTECs (White et al., 2010).

In contrast to mTECs, the developing stages of CTECs 
remain poorly defined. So far, the understanding about cTEC development is as follows: TEPCs in thymus organogenesis first develop into progenitors specific for cTECs (cTEPCs) phenotypically characterized as $\mathrm{EpCAM}^{+} \mathrm{CD} 205^{+} \mathrm{CD} 40^{-} \mathrm{MHCl}^{-}$. Unlike the common progenitors, cTEPCs could self-renew after thymus injury (Rode and Boehm, 2012). Concomitant with cTECs maturation, CD40 and $\mathrm{MHCll}$ expression are upregulated. Mature cTECs express a series of protease participating in thymocytes positive selection (Murata et al., 2008). Such as thymoproteasome containing $\beta 5 t$ promotes the generation of $\mathrm{MHCl}^{-r e s t r i c t e d ~} \mathrm{CD}^{+} \mathrm{T}$ cells (Murata et al., 2007; Shakib et al., 2009; Takahama et al., 2012). $\beta 5$ t expression is first detected in thymus on E12.5. $\beta 5$ t expression in cTECs requires Foxn1 expression but not medulla formation (Ripen et al., 2011). Other proteases like Cathepsin- $L$ and thymusspecific serine protease (TSSP) mediate selection of MHCIIrestricted $\mathrm{CD}^{+}{ }^{+} \mathrm{T}$ cell development (Nakagawa et al., 1998; Gommeaux et al., 2009; Viret et al., 2011). The major development/differentiation stages of cTECs and mTECs and their related molecular markers were briefly summarized in Figure 1.

\section{MECHANISMS THAT CONTROL TEC DEVELOPMENT}

TEC development is a very complex process with a sophisticated regulatory network, which includes extrinsic and intrinsic signals. Extrinsic signals are essentially required for TEC development and differentiation. Among Tumor necrosis factor receptor (TNFR) family members, the receptor activator for NFKB (RANK), CD40 and lymphotoxin $\beta$ receptor (LT $\beta R$ ) especially determine the $\mathrm{mTEC}$ formation and development. Meanwhile, fibroblast growth factor (FGF) and Wnt promote TEC expansion and functional maintenance. Intrinsic molecules in TECs, such as transcription factor Foxn1 and Aire are essential for TEC development and functional maturation. In addition, other molecular signals may not determine TEC development, but deficiency in any of them also affects the efficiency of TEC development and differentiation. Herein, we will discuss some of the important extrinsic and intrinsic signals in TEC development one by one.

\section{Extrinsic signals involved in TEC development}

TEC development is definitely dependent on their interaction with other cells in thymus such as thymocytes, fibroblasts and mesenchymal cells. These cells will offer important extrinsic signals for TEC differentiation such as TNFR ligands, FGFs and Wnts.

\section{TNFR}

TNFR superfamily members and their ligands play an essential

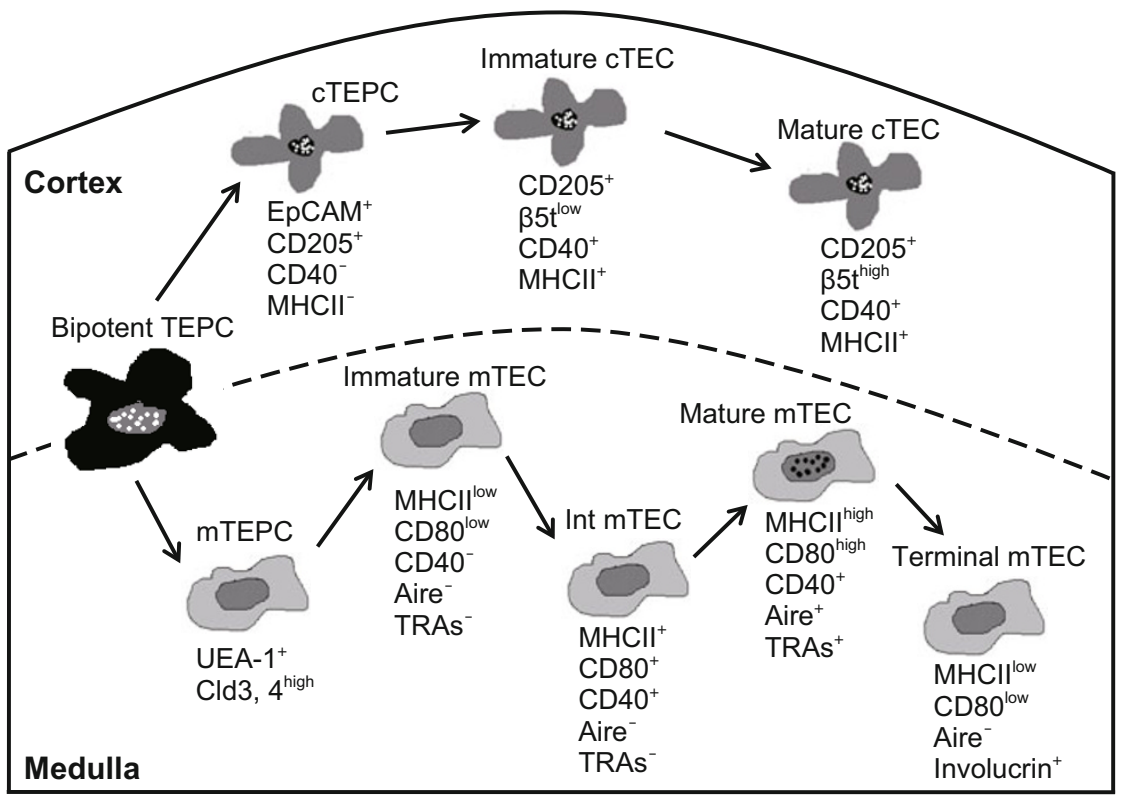

Figure 1. A summary of TEC development stages and their related molecular markers. mTECs and cTECs are derived from common bipotent progenitors (TEPCs) possibly located at cortico-medullary junction. In thymic medulla, TEPCs first develop into progenitors specifically for mTECs characterized as high expression of claudin-3 and claudin-4 (UEA- $1^{+} \mathrm{Cld} 3,4^{\mathrm{hi}}$ ). The development of mTECs is divided into four stages: immature mTEC express low level of $\mathrm{MHCll}$ and costimulatory molecules CD80/40. As mTECs develop further into middle mature stage, $\mathrm{MHCll}$ and $\mathrm{CD} 80 / 40$ are up-regulated but still without Aire expression. The full mature mTECs are highly expressed $\mathrm{MHCll}$ and $\mathrm{CD} 80$ and Aire (UEA- $1^{+} \mathrm{MHCl} /{ }^{\mathrm{hi}} \mathrm{CD} 80^{\text {hi }}$ Aire ${ }^{+}$) as well as up-regulation of Aire-dependent and -independent tissue-restricted antigens (TRAs). Finally, mature mTECs enter into terminal differentiation to Aire ${ }^{-} \mathrm{CD} 80^{\text {int }} \mathrm{MHCll}^{\mathrm{lo}}$ involucrin ${ }^{+}$stage. On the other hand, progenitors for $\mathrm{cTECs}$ are characterized as $\mathrm{EpCAM}^{+} \mathrm{CD} 205^{+} \mathrm{CD}^{-} 0^{-}$. Concomitant with cTECs mature, $\mathrm{CD} 40$ and $\mathrm{MHCll}$ are upregulated. Mature cTEC express a series of protease such as $\beta 5 t$ participating in thymocytes positive selection. 
role in TECs especially mTECs development (Akiyama et al., 2012). mTECs express a diverse set of TNFR, three of these including RANK, CD40 and LTRR have been proven to be extremely important in medulla formation and $\mathrm{MTEC}$ development.

RANKL-RANK signaling initiates the mTEC formation and maturation. In the embryonic thymus, RANKL signals provided by $\mathrm{CD}^{+} \mathrm{CD}^{-}$lymphoid tissue inducer (LTi) cells and invariant $\mathrm{V} 5^{+}$dendritic epidermal T cells (DETCs), promote CD80Aire ${ }^{-} \mathrm{mTEC}$ developing into $\mathrm{CD} 80^{+} \mathrm{Aire}^{+} \mathrm{mTECs}$ (Rossi et al., 2007b; Roberts et al., 2012). In the postnatal thymus, RANKL signal is provided mainly by positively selected $C D 4^{+} \mathrm{T}$ cells. Disruption of the RANKL-RANK signaling in postnatal thymus leads to reduction of mature UEA $-1^{+} \mathrm{CD} 80^{\text {hi }} \mathrm{MHCII}$ hi mTECs and autoimmue disease (Akiyama et al., 2008; Hikosaka et al., 2008). In contrast, mice deficient for osteoprotegerin (OPG, a decoy receptor for RANKL) developed thymic hyperplasia and more mature mTECs (Hikosaka et al., 2008). Transplantation of RANKL ${ }^{-/}$thymus or transferring their splenocytes into immune deficient mice caused severe inflammatory cell infiltration and abundant production of autoimmune antibody (Rossi et al., 2007b; Akiyama et al., 2008). So the abnormality of RANKL-RANK signaling results in mTEC development arrest and failure of self tolerance.

CD40L-CD40 signaling pathway is essential for the formation of a complete and functional thymic environment. In the postnatal thymus, CD40L is provided by positively selected thymocytes $\left(\mathrm{CD}^{+}\right.$and $\mathrm{CD}^{+} \mathrm{T}$ cells). It is suggested that in CD40- or CD40L-deficient mice, mature mTECs were obviously decreased. Although the defects are less severe compared to mice deficient in RANK signaling. CD40 ${ }^{-/} \mathrm{RANKL}^{-1-}$ double deficient mice displayed a greater reduction in mature mTECs and more severe autoimmune disease, implying that RANK and CD40 act cooperatively in modulation of thymic medullary microenvironment and self-tolerance (Akiyama et al., 2008; Hikosaka et al., 2008; Irla et al., 2008).

Another important TNFR, LT $\beta R$ signaling is indispensible for many lymphoid organogenesis including lymph node, Peyer's patches and spleen (Futterer et al., 1998; Endres et al., 1999). In the thymus, LT $\beta R$ is mainly expressed on thymic stromal cells other than $T$ and $B$ lymphocytes. Two ligands for LT $\beta R$ are discovered: LTa1 22 and LIGHT, in which the former consist of LTa and LT $\beta$ subunits. The mature single positive thymocytes are the main source for LTRR ligand in the thymus (Irla et al., 2008).

The importance of lymphotoxin signaling in mTEC development is confirmed. Mice deficient in LT $\beta R$, its ligand or downstream signal molecule nuclear factor-KB-inducing kinase (Nik) caused defects in thymic medulla development including disorganized medullary architecture, significant reduction in overall mTECs and retention of $T$ cell maturation with autoimmune disease (Boehm et al., 2003; Venanzi et al., 2007). However, there are still controversy in the role of lymphotoxin signaling in Aire and TRAs expression. Previous work showed that lymphotoxin signaling is required for Aire and Aire-dependent as well as Aire-independent TRA expression (Chin et al., 2003).
The following research, by whole genome transcriptome analysis, indicated that lymphotoxin signaling does not regulate Aire and Aire-dependent TRAs expression in mTECs (Martins et al., 2008). The distribution of regulatory $T$ cells (Tregs) and DCs are also not affected. LTa or LT $\beta$ deficient mice showed normal CD80, CD40 and Aire as well as TRAs expression despite reduced medulla area (Martins et al., 2008; Seach et al., 2008). In addition, lymphotoxin signaling participates in regulating gene expression that is independent on Aire. Such as type II collagen expression in mTECs is lymphotoxin-dependent but Aire-independent (Chin et al., 2006; Seach et al., 2008). These data suggest that in regulating $\mathrm{mTEC}$ development, lymphotoxin signaling and Aire may not be correlated (Venanzi et al., 2007). The inconsistent results regarding lymphotoxin signaling and Aire might be due to different TCR transgenic models used in different studies and the different detecting measures used in those studies (Zhu et al., 2010). Despite the obvious similarities between LT $\beta$ R and its ligand (LTa, LT $\beta$, and LIGHT) deficient mice, the receptor-deficient mice appears to have more severe defects in medulla. This result give us the assumption that there may be other ligands for LT $\beta R$ involved in mTECs development (Boehm et al., 2003).

Several advances have recently been made in understanding the role of lymphotoxin signaling in embryonic mTEC development (Zhu et al., 2010). It is widely accepted that mTEC development relies on RANK signaling. One recent study investigated the cooperative action of individual TNFR superfamily members. The results showed that the LT $\beta R$ signal could up-regulate RANK expression in the thymic stroma, thereby promoting RANK signaling and $\mathrm{mTEC}$ differentiation. They also revealed a type of cooperation between the LT $\beta R$ and RANK signals, because the mTECs defects in RankI/LTKR double knockout mice were more severe than each single deficient mice (Mouri et al., 2011).

Moreover, lymphotoxin signaling also plays a role in terminal differentiation of mTECs (involucrin ${ }^{+}$). Aire expression and terminal differentiation of mTEC lineage are temporally separable events which are controlled by distinct mechanisms. Initial Aire ${ }^{+}$mTEC development depends upon RANK signaling while continued mTEC development into the involucrin ${ }^{+}$ stage required for activation of the LTa-LT $\beta R$ signal provided by mature thymocytes (White et al., 2010). It seems that LT $\beta R$ signals indirectly influence mTECs through regulating other stromal cells like MTS15 ${ }^{+}$fibroblasts which expressed the highest LT $\beta R$ level than TECs (Seach et al., 2008).

Among three TNFR signals, RANKL-RANK signal plays the leading part in mTEC development. RANK signal determines the formation of mTECs and medulla. The lymphotoxin signal could elicit RANK expression at this time. mTEC development at postnatal thymus needs cooperation between RANK, CD40 and LT $\beta R$. Besides, LT $\beta R$ regulates $m T E C$ terminal differentiation. In conclusion, all TNFR signals cooperatively control the thymic medullary microenvironment and self-tolerance establishment. 


\section{FGFs}

Cell expansion is required for establishment of a complete and functional thymic microenvironment supporting thymocyte development. FGFs boost thymopoiesis as well as promote differentiation by working on both thymocytes and TECs. Ectopic FGF8 expression caused thymus hypoplasia (Frank et al., 2002). FGF8 influence TECs indirectly by regulating neural crest cells (NCCs) survival and differentiation, therefore FGF8 deficiency and NCCs deletion result in similar manifestation (Bockman and Kirby, 1984). FGF7 and FGF10 conduct mainly as nutritional factors promoting TECs proliferation but not differentiation. Loss of FGF10 also causes inhibition of thymus development, and alters thymic cytokeratin expression pattern (Revest et al., 2001). Development of thymus deficient in FGF receptor R2-IIlb (FGFR2IIIb) - receptor for FGF7 and FGF10, is blocked at E12.5 when TECs just emerge. However, FGF signal is not always enhancing TECs. When thymus and parathyroid glands are derived from the third pharyngeal pouch endoderm, localized inhibition of FGF signaling is essential for normal Gcm2, Bmp4 and Foxn1 expression and thymus/parathyroid detachment (Gardiner et al., 2012).

Among FGFs, major research interests focused on FGF7, also known as keratinocyte growth factor (KGF) which boosts thymus architecture and global function. In the thymus, mature $\mathrm{CD}^{+}$and $\mathrm{CD}^{+}$thymocytes and fibroblasts are main source for KGF. KGF acts on both thymocytes and TECs, promoting their proliferation and function. KGF administration to intact adult mice resulted in a transient expansion of both immature and mature TECs, leading to T cell generation (Rossi et al., 2007a). KGF in the thymus of RAG-deficient mice is very low due to absence of thymocytes, leading to thymus hypoplasia, while adding KGF could increase medullary compartment (Erickson et al., 2002). Furthermore, administration of KGF protected thymus damage from radiation or graft-versus-host disease thus enhanced immune reconstitution after hematopoietic stem cell transplantation (Min et al., 2002; Rossi et al., 2002; Alpdogan et al., 2006). Therefore, KGF attenuates thymic aging in elderly individuals, protecting medullary architecture and promoting T cell production (Min et al., 2007; Berent-Maoz et al., 2012).

Thymic mesenchymal cells also regulate thymus growth by producing FGFs. By E12 of gestation, thymus rudiment is surrounded by mesenchyme derived from NCCs (Auerbach, 1960). Mesenchymal cells migrate into thymus at E13 to differentiate into many cell types like fibroblasts, modulating TECs and thymocyte development (Suniara et al., 2000). Removal of mouse perithymic mesenchyme at E12 did not affect differentiation of immature TECs, but reduced TEC cell number. Mesenchymal cells enhance TEC proliferation by producing FGF7 and FGF10. Mesenchyme deletion did not affect TEC differentiation, suggesting that the mechanism underlying TEC proliferation and differentiation is disconnected (Jenkinson et al., 2003). Via activation of p53 and NF-kB signal pathway, KGF regulates a series of genes associated with TEC function and $\mathrm{T}$ cell development, including BMP2, BMP4, Wnt5b and Wnt10b (Rossi et al., 2007a).

\section{Wnt}

In the thymus, Wnt receptors are exclusively expressed on TECs (Balciunaite et al., 2002), indicating the crucial role for Wnt signaling in TEC development and function. Firstly, Wnt participates in TECs development by regulating Foxn1 expression. In addition, growing data indicate that Wnt4, induction of both classical and non-classical Wnt signaling, plays an essential role in maintaining thymic microenvironment. In the fetal thymus, Wnt4 is expressed in TECs and fibroblasts, while in adult thymus, Wnt4 is predominantly produced by TECs including both mTECs and cTECs (Heinonen et al., 2011a). Wnt4 controls thymopoiesis and thymus size by regulating TEC, thymocyte and their progenitor proliferation (Heinonen et al., 2011a; Heinonen et al., 2011b). Wnt4 protects thymus (TECs) from injury induced by dexamethasone (Talaber et al., 2011). In contrast, over-expression of DKK1, a inhibitor of Wnt4 in TECs, leads to thymic atrophy, reduction of TEPCs and TEC proliferation, all features similar to thymic aging (Osada et al., 2010). Therefore, Wnt4 become a marker for thymic senescence (Kvell et al., 2010). With ageing, the expression of Wnt4 and its downstream target gene Foxn1 are down-regulated. Another Wnt4 target gene, connective tissue growth factor (CTGF) is potentially involved in a negative feed-back loop suppressing Wnt expression, which is important for initiation of thymic senescence (Varecza et al., 2011).

Except for the factors mentioned above, other signals are of great importance in TEC development as well. Notch signaling represents one important molecular example for thymic crosstalk. Notch signals provided by thymocytes induce the development of thymic microenvironments (Masuda et al., 2009). The vitamin A metabolite and transcriptional modulator retinoic acid (RA) is recently recognized as an important regulator of epithelial cell homeostasis in many other tissues. RA signaling is a preliminary requirement for thymopoiesis (Wendling et al., 2000), while ectopic expression of RA cause thymic hypoplasia (West et al., 1989). Mesenchymal cells are identified as the major source of RA in the embryonic thymus. It seems that RA modules TECs turnover in a suppressive way in which RA signaling promotes TECs cell-cycle exit and restricts TECs cellularity preferentially in the cTEC compartment (Sitnik et al., 2012).

\section{Intrinsic signals involved in TEC development}

Intrinsic signals have been identified for TEC development. In the following section, we will focus on Foxn1, Aire and NF-kB, and give a brief introduction on other related molecules.

\section{Foxn1}

With no doubt, transcriptional factor Foxn1 plays a crucial role in thymus (and TECs) development. Mice that are deficient in 
Foxn1 (Foxn1 ${ }^{\text {nu/nu }}$, nude mice) have atrophic thymus and few T cell production, leading to severe immune deficiency (Blackburn et al., 1996). Foxn1 expression was first detectable on E11.25 in mice, the stage between thymus anlage formation and TEC development (Bennett et al., 2002). Foxn1, expressed on almost all TECs, regulates TEC (including mTECs and cTECs) differentiation and function in the fetal and adult thymus (Nehls et al., 1994).

A series of transgenic mouse models related to Foxn1 allele significantly extend our understanding on its function. In Foxn $1^{\text {nu/nu }}$ mice, the earliest stage of thymus development was not impaired, in which the common progenitors could persist even in the postnatal thymus. However, thymus development was arrested after initial formation of the organ anlage (about E12 in mice) without hematopoietic precursors colonization (Cordier and Heremans, 1975). While the reversion of Foxn1 expression resulted in a functional thymus compartments with both cortical and medullary tissues (Bleul et al., 2006). Foxn $1^{\Delta / \Delta}$ is a transgenic mice with a hypomorphic Foxn1 allele, lacking exon 3 and thus the $\mathrm{N}$-terminal domain of Foxn1. Unlike nude mice, affection in Foxn $1^{\Delta / \Delta}$ is thymusspecific and much milder, while the skin and hair development is normal (Su et al., 2003). The thymus was highly cystic, containing no discernable cortical or medullary regions. As a result, the thymocyte development was also blocked although the hematopoietic stem cells could colonize in the thymus (Su et al., 2003). In Foxn $1^{\text {LacZ }}$ mice, the postnatal Foxn1 transcription is disrupted by LacZ gene inserted in the 3 '-untranslated region of the Foxn1 gene locus. The Foxn1 expression is normal through the newborn stage, but descends gradually with age. When the down-regulation of Fonx1 was below $50 \%$, the thymus atrophy occurred with lower TECs and $\mathrm{T}$ cells in Foxn1 dosage-sensitive manner. Because of high Foxn1 expression, the mature population of mTECs $\left(\mathrm{MHClI}{ }^{\mathrm{hi}} \mathrm{UEA}-1^{\mathrm{hi}}\right)$ is more sensitive to Foxn1 regulation (Chen et al., 2009). TEC development blockage was concomitant with impaired $\mathrm{T}$ cell production, leading to lower immune-surveillance to infection and aging phenotype (Guo et al., 2012). However, the mechanisms for reduced Foxn1 expression in this mutant are uncertain, because the inserted LacZ gene is not controllable. In addition, LacZ insertion may disrupt other developmental process. So mouse models with conditionally deletion of Foxn1 (Foxn1 ${ }^{\mathrm{fx}}(\mathrm{fx})$ ) offered us a better opportunity to understand the Foxn1 function (Cheng et al., 2010). Ubiquitous deletion of Foxn1 after birth caused dramatic thymic atrophy in 5 days with more severe defects in MTECs (especially the $\mathrm{MHCI}{ }^{\text {hi }} \mathrm{UEA}-1^{\text {hi }}$ mature population) than cTECs. The loss of TECs resulted from increased apoptosis due to activation of p53 gene. Interestingly, when Foxn1 deletion was driven by $\mathrm{K} 5$ promoter (expressed mainly on mTECs), similar results were seen, whereas Foxn1 deletion in K18 promoter-driven (mostly cTECs) was not. This may suggest that Foxn1 is more important for the maintenance of mTECs in the postnatal thymus. By crossbreeding Foxn $1^{\mathrm{fx}}(\mathrm{fx})$ mice with ubiquitous promoterdriven Cre-recombinase transgenic mice, $\mathrm{fx} / \mathrm{fx}-\mathrm{uCreER}^{\top}$ mice undergoing spontaneous Foxn1 deletion with age was established. It was demonstrated that age-related loss of Foxn1 caused thymic epithelial cysts in medulla and perturbed negative selection, due to reduced Aire expression (Xia et al., 2012). Recently, Foxn $1^{\mathrm{R}}$ is a revertible hypomorphic allele of Foxn1, by crossing Foxn $1^{R}$ mice with Foxn $1^{-1-}$ or wide-type mice, a series of six strains comprising all possible combinations of Fonx1 alleles and thus with different Foxn1 expression level were established. By analysis of these mice, the authors suggested that no evidence for a role for Foxn1 in TEC fate-choice was found. Rather, Foxn1 is required for stable entry into both the cortical and medullary TEC development lineages in Foxn1 dosage-dependent manner (Nowell et al., 2011). Overexpression of Foxn1 (Foxn1Tg mice) attenuated age-induced thymic involution. In old Foxn1Tg mice, age-associated thymic atrophy was diminished, and the total number of $\mathrm{EpCAM}^{+}$and $\mathrm{MHCl}^{\mathrm{hi}}$ TECs were higher (Zook et al., 2011). Overall, these results demonstrated a cell autonomous requirement for Foxn1 in development of all major TEC sub-lineages. All those genetically modified mice and their thymic phenotypes are summarized in Table 1.

Collectively, the above data suggest that Foxn1 is a powerful regulator of TECs development required at multiple stages of both cTECs and mTECs differentiation. First, Foxn1 is dispensable for earliest progenitors presence but indispensable for mTEC and cTEC development (Nowell et al., 2011). So it is not surprising that the earliest TEPCs persist in Foxn $1^{-1-}$ thymus, but the development from progenitor cells into cTEC and mTEC sub-lineages is arrested, indicating that Foxn1 plays a role in regulating TEC differentiation but not the progenitors appearance (Blackburn et al., 1996). Second, Foxn1 also modulates the differentiation of both cTEC and mTEC sub-lineage in the postnatal thymus. Third, Foxn1 participates in TEC survival and proliferation (Itoi et al., 2001; Chen et al., 2009) and terminal differentiation (Baxter and Brissette, 2002; Janes et al., 2004; Nowell et al., 2011). Finally, Foxn1 expression is related to age-associated thymic atrophy, indicating its regulatory role in thymus senescence.

In addition to the function in regulating TEC development, Foxn1 could also make contributions to the vascularization of the murine thymus. VEGF, an endothelial cell mitogen, is mainly produced by thymic epithelial cells and mesenchymal cells. Upon binding to VEGF, endothelial cells are induced to proliferate, forming structural support surrounding vessels. As in the nude thymus, neither CD $31^{+}$endothelial cells nor VEGF producing mesenchymal cells are detected in the epithelial region (Mori et al., 2010).

As a transcriptional factor, Foxn1 directly or indirectly regulates a series of genes involved in diverse aspects of thymus development or function (Nowell et al., 2011). Pax1, expressed on the third pharyngeal pouch at E9.5, essentially regulates TECs differentiation and proliferation (Su et al., 2001). The expression of Pax1 in the thymus primordium is Foxn1-dependent. Foxn1 also regulates genes closely associated with thymocyte development. CCL25 and CXCL12, chemokines 
Table 1. Mouse models with different Foxn1 allele

\begin{tabular}{|c|c|c|c|}
\hline Foxn1 allele & Foxn1 status & Phenotype & Reference \\
\hline Foxn1 $1^{\text {nu/nu }}$ & No Foxn1 expression & $\begin{array}{l}\text { Thymus atrophy } \\
\text { Hairless } \\
\text { TECs development blocked } \\
\text { at bipotent progenitor stage } \\
\text { No HSC colonization }\end{array}$ & Sitnik et al., 2012 \\
\hline Foxn1 ${ }^{\Delta / \Delta}$ & Lacking N-terminal domain & $\begin{array}{l}\text { Normal skin and hair } \\
\text { Cystic thymus } \\
\text { No cortical or medullary regions } \\
\text { Blocked thymocyte development }\end{array}$ & Blackburn et al., 1996 \\
\hline Foxn1 $1^{\text {lacZ }}$ & Descend gradually with age & $\begin{array}{l}\text { Fonx } 1 \text { below } 50 \% \text { : } \\
\text { Thymus atrophy } \\
\text { Lower TECs and T cell }\end{array}$ & Bennett et al., 2002 \\
\hline $\operatorname{Foxn}^{1 \mathrm{fx}}(\mathrm{fx})$ & Conditionally deletion & $\begin{array}{l}\text { Ubiquitous deletion of FoxN1: } \\
\text { Dramatic thymic atrophy in } 5 \text { days } \\
\text { Loss of mTECs } \\
\text { More defects in mature mTECs than cTECs }\end{array}$ & Cordier et al., 1975 \\
\hline $\mathrm{fx} / \mathrm{fx}$-uCreER ${ }^{\top}$ & Spontaneous deletion with age & $\begin{array}{l}\text { Thymic epithelial cysts in medulla } \\
\text { Reduced Aire expression } \\
\text { Perturbed negative selection }\end{array}$ & Su et al., 2003 \\
\hline Foxn1 $^{\mathrm{R}}$ & $\begin{array}{l}\text { Revertible hypomorphic allele } \\
\text { Establishment of six strains } \\
\text { with different Foxn1 levels }\end{array}$ & $\begin{array}{l}\text { Fonx } 1 \text { is required at multiple intermediate } \\
\text { stages of TE lineage development } \\
\text { Dispensable for TEC fate-choice }\end{array}$ & Chen et al., 2009 \\
\hline Foxn1Tg & Over-expression of Foxn1 & $\begin{array}{l}\text { In aged mice: } \\
\text { Thymic atrophy was diminished } \\
\text { More TECs and } \mathrm{MHCI}{ }^{\mathrm{hi}} \text { TECs }\end{array}$ & Guo et al., 2012 \\
\hline
\end{tabular}

modulating hematopoietic stem cell localization in thymus (Liu et al., 2006; Calderon and Boehm, 2012), and stem cell factor (SCF), promoting $\mathrm{T}$ cell progenitor growth, were undetectable in Foxn1-deficient thymus. Foxn1 deficiency also caused diminishment of another factor DLL4, a ligand for Notch which controls hematopoietic stem cells specifically differentiated into early T cell progenitors (Koch et al., 2008; Calderon and Boehm, 2012). In addition, CathepsinL, CD40 and MHCII involved in TEC development and function are regulated by Foxn1 directly or indirectly (Nowell et al., 2011).

On the other hand, the expression and maintenance of Foxn1 gene in the thymus is strictly under control, in which wingless (Wnt) and bone morphogenic proteins (BMPs) play an important role. Wnts are a large family of secreted glycoproteins participating in many aspects of cellular development including cell fate determination, migration, proliferation, polarity and death (Wodarz and Nusse, 1998). In the thymus, mostly Wnt4 and Wnt5b, produced by TECs and thymocytes, regulate Foxn1 expression in TECs through both autocrine and paracrine manners through TCF-4 and LEF-1 (Balciunaite et al., 2002). BMPs are members of TGF- $\beta$ superfamily and act as morphogens in the development of many organs. By analyzing the expression pattern of BMP4 in the third pharyngeal pouch, it was revealed that BMP4 expression localized on the third pharyngeal pouch endoderm at E10.5, in which cells that would form thymus expressing Foxn1 (Patel et al., 2006). Overexpression of Noggin, an antagonist of BMP4 in TECs leads to atrophic thymus and small number of thymocytes (Bleul and Boehm, 2005). In fetal thymic organ culture (FTOC), BMP4 promotes Foxn1 expression on TECs and thereby improving thymic microenvironment for thymopoiesis (Tsai et al., 2003).

\section{Aire}

The animal model of autoimmune polyendocrinopathy (APECED) characterized by polyglandular autoimmune disease revealed a very important factor, Aire, participating in $\mathrm{T}$ cell tolerance induction in the thymus. Aire is not only a marker for mature mTECs, but also regulates mTEC development and differentiation (Mathis and Benoist, 2009). Aire-deficient mice showed morphological changes in medullary components with decreased mTECs. A fate-mapping strategy allowing permanent marking of cells expressing Aire, enabled us to distinguish mTECs committed to expressing Aire from Aire-nonexpressing mTECs. It is demonstrated that the numbers of mTECs expressing involucrin, a marker for terminal epidermal differentiation, were reduced in Aire-deficient thymus, which 
was associated with nearly an absence of $\mathrm{HC}$-like structures in the medulla (Hikosaka et al., 2008). All these data suggest that Aire controls the differentiation program of mTECs. mTECs lack of Aire ceased to differentiate further, thereby remained at the pre-mature stage just before terminal differentiation (Yano et al., 2008).

The most important function of Aire is as a transcription factor regulating expression of a panel of peripheral self-antigen in $\mathrm{mTECs}$ and promoting the antigen presentation ability of mTECs, participating in T cell negative selection and self tolerance establishment (Gardner et al., 2009). Therefore, Aire deficiency caused a severe autoimmune disease manifestation with inflammatory cell infiltration in multiple organs and autoimmune antibody production (Anderson et al., 2002; Ramsey et al., 2002). Aire regulates TRAs expression in multiple manners, among them there are mainly multiple pathways (DansoAbeam et al., 2011). 1) Aire as a classical transcription factor, which could initiate transcription of target genes by binding to their promoter region. 2) Aire increases TRAs expression nonspecifically by loosening up the chromatin structure. 3) Aire functions through epigenetic modification. Aire recognizes epigenetic site of unmethylated histone 3. Following demethylation, Aire enhances target gene transcription either via itself directly or via recruiting other transcriptional activators indirectly. Apart from these 3 ways mentioned above, the mRNA levels of Aire in mTECs could determine the expression of peripheral tissue antigen genes (Oliveira et al., 2012). Microarray analysis of expression pattern of wild-type and Aire ${ }^{-/}$mTECs revealed that Aire could induce transcription of target genes by unleashes stalled RNA polymerase in mTECs (Giraud et al., 2012). In addition to TRAs, Aire also controls the expressions of microRNAs in mTECs (Macedo et al., 2012), which in turn play a crucial role in maintaining normal thymic microenvironments. TECs with a deficiency of Dicer, an enzyme catalyzing the formation of miRNA caused decreased thymus thymopoiesis and impaired negative selection and thus autoimmune disease (Zuklys et al., 2012).

Interestingly, in Aire-deficient thymus, an increase of mTECs expressing truncated Aire protein occurred (Dooley et al., 2008), indicating that these mTECs would be eliminated in wide-type thymus. This data shed light on Aire's proapoptotic activity. Another evidence was deduced from the fact that overexpression of Aire in an mTEC line caused overt apoptosis of the cells (Gray et al., 2007). The mechanism of this proapoptotic activity is in part associated with nuclear translocation of stress sensor and proapoptotic protein GAPDH (Liiv et al., 2012).

\section{$N F-K B$}

The signaling pathway downstream of RANK, CD40 and LT $\beta R$ is usually canonical/non-canonical NF-kB signal (Basak and Hoffmann, 2008). There are five members in NF-kB family namely, NFkB1 (p150/p50), NFkB2 (p100/p52), c-Rel, RelA and RelB. In the thymus, NFKB1 and RelA are mainly localized in cortical areas whereas NFKB2, c-Rel, and RelB are in the medulla (Manley and Condie, 2010). Both canonical and noncanonical NF-kB signal pathways regulate mTEC development (Zhu and Fu, 2010). RANK and CD40 on mTECs initiate activation of the classical NF-KB pathways via TNF receptor associated factor 6 (TRAF6). TRAF6-deficient mice showed severe destruction of medullary architecture and loss of UEA $-1^{+}$mTECs (Akiyama et al., 2005). As a cascade, TRAF6 activates TGF- $\beta$ activating kinase 1 (TAK1), which in turn phosphorylates the IKK complex composed of IKKa, IKK 3 and NEMO. Subsequently, the IKK complex phosphorylates IkBa for degradation, leading to translocation of the RelA/p50 complex to the nucleus. All RANK, CD40 and LTßR signaling could elicit non-classical NF-KB pathways via TRAF2/5 to activate p52/RelB (Irla et al., 2009). In non-classical NF-kB pathways, IKKa is phosphorylated by NIK, which in turn induce p100 degradation to p52. Together with RelB, p52 then were translocated to nucleus. Accordingly, mice deficient of genes related to non-classical NF-KB pathways including NIK, IKKa, and RelB also had abnormal thymus development with reduced UEA $-1^{+}$and/or Aire ${ }^{+}$mTECs (Burkly et al., 1995; Weih et al., 1995; Kajiura et al., 2004; Kinoshita et al., 2006; Lomada et al., 2007). NF-kB2-deficient mice display a remarkable decrease in the number of mature mTECs $\left(C D 80^{\text {hi }}\right)$ and Aire expression, leading to severe autoimmune phenotype (Zhang et al., 2006; Zhu et al., 2006).

\section{Other molecules related to TEC development}

Except for transcription factors mentioned above, other inner molecular signals are involved in TEC development and differentiation too. $\mathrm{Sin}$ is a signaling adapter protein and regulates signaling by mediating protein-protein interactions (Alexandropoulos et al., 2003). Sin is expressed specifically in the mTECs but not in cTECs. $\mathrm{Sin}^{-1-}$ mice showed autoimmune manifestations correlated with disorganized medullary architecture and reduced functionally mature mTECs under steady-state conditions. Sin deficiency inhibits the expansion of mTECs in response to KGF (Danzl et al., 2010; Alexandropoulos and Danzl, 2012). As an adaptor protein, Sin regulates Erk1/2 activation downstream of the KGF/FGFR2Illb, leading to the enhancement of TEC proliferation. In addition, Sin activates p52 (non-classical NF-KB pathway) to promote MTEC survival and differentiation (Alexandropoulos and Danzl, 2012).

Spatial is expressed in thymic stromal cells and regulates TEC proliferation and thymus size (Flomerfelt et al., 2000, 2010; Saade et al., 2010). RhoB, a member of small GTPases family, is also expressed in thymic medullary epithelium. Mice deficient in RhoB were found to display earlier thymic atrophy (Bravo-Nuevo et al., 2012). p63, a homologue of the tumor suppressor p53 and considered as a marker for TEC progenitors, is pivotal for epithelial development. Because its loss causes severe thymic atrophy and component disorder (Candi et al., 2007b). p63 is required for TEPCs to keep their proliferative capacity by inhibiting TEPCs apoptosis (Candi et 
al., 2007a; Senoo et al., 2007). The ADAMs (a disintegrin and metalloproteases) family of transmembrane proteins belongs to metalloproteinase, and is involved in thymus development. Mice with a deletion of Adam 10 specifically in TECs (driven by K14-cre) caused thymic atrophy (Weber et al., 2011). TECs deficient in Adam17 (Foxn1-cre) specifically reduced Aire expression but not affected TECs and T cells development (Gravano et al., 2010). Furthermore, deficiency in Adam8 results in accumulation of single positive thymocytes in the thymus and lower cortex/medulla ratio, due to the increased mTECs (Gossens et al., 2010).

\section{CONCLUDING REMARKS}

Multiple signals and cellular interactions play a crucial role for TEC complete development during thymus organogenesis. The epithelial/mesenchymal interactions and cross-talk of TECs with other cells such as lymphoid cells are required for maturation/expansion/maintenance of epithelial compartments, especially for mTEC development. TNFR signals of RANKL, CD40L and lymphotoxin are mostly provided by mature thymocytes, while the FGFs, RA are produced by mesenchymal cells (Fig. 2). Foxn1 is a powerful intrinsic modulator of TEC lineage progression in both fetal and adult thymus in a dosagedependent manner. The multiple signal pathways regulating TEC development are briefly summarized in Fig. 2.

Although we generally know the cellular and molecular hierarchies in TECs lineage development, thymic microenvironment however is a complicated network concluding interaction between many cell types and signal molecules. Many questions are still waiting to be answered. Such as, what is the exact developmental pathway for both cTECs and mTECs? Aire ${ }^{+} \mathrm{CD} 80^{+} \mathrm{mTECs}$ represent all mTECs or just a population of them? When and how the thymic cross talk is established? What is the underlying molecular mechanism for all the events in TECs development? Understanding the mechanisms that drive TEC differentiation and function would offer the possibility

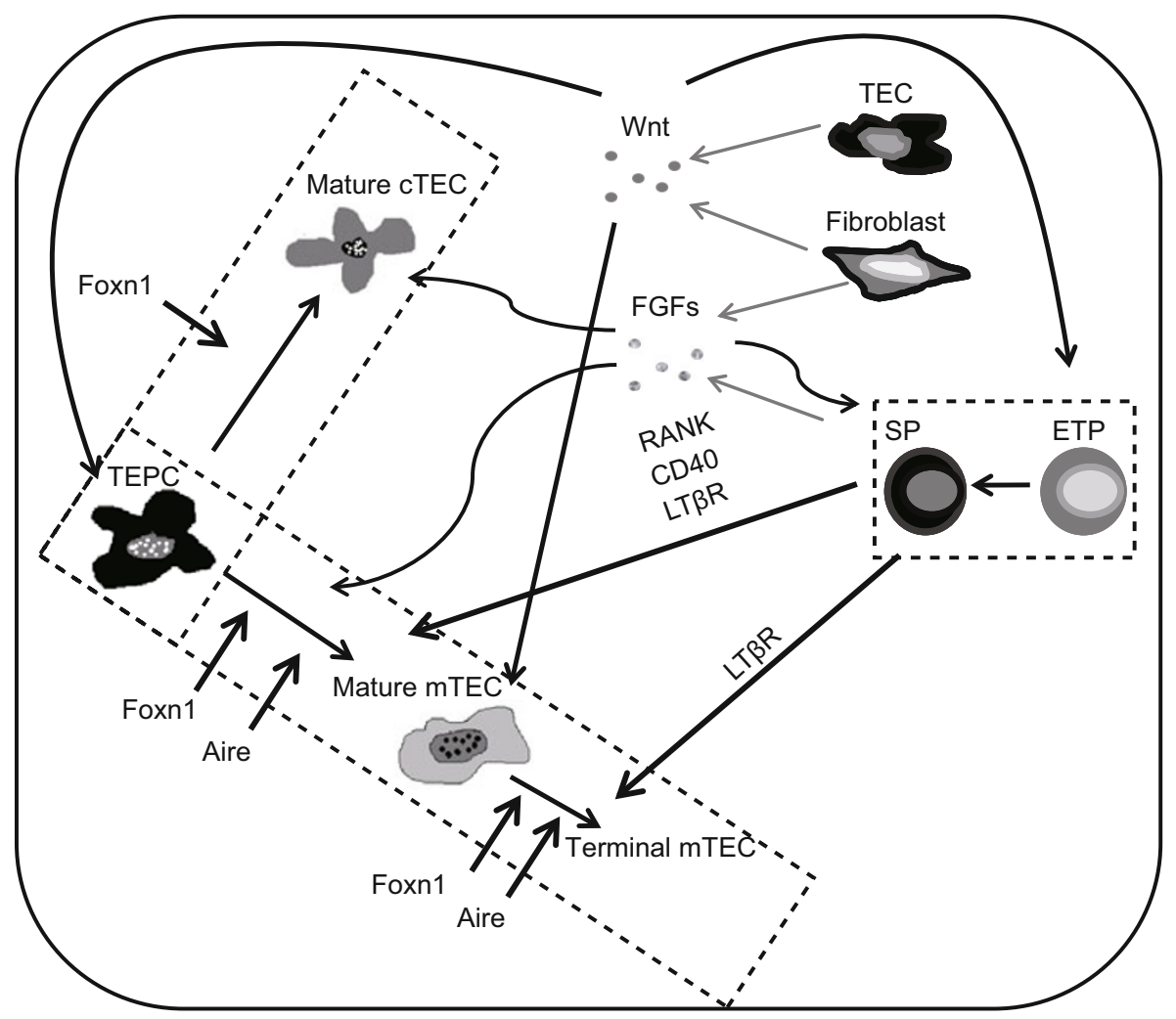

Figure 2. Extrinsic and intrinsic signals regulating TEC development. mTECs and CTECs share a common bipotent progenitors (TEPCs) during thymus organogenesis. Apart from the presence of earliest progenitors and entry into differentiation programme, transcription factor Foxn1 regulates TECs development at almost every stages of cTECs and mTECs. Aire is a marker for mature mTECs as well as promotes mTEC development, maturation and terminal differentiation. Extrinsic signaling through cellular crosstalk are also involved in TEC development. TNFR family members including RANK, CD40 and LT $\beta R$ signals cooperatively participate in thymic medulla formation and mTEC development. Moreover, LTßR regulates mTEC terminal differentiation. The ligands for TNFR are provided by positively selected thymocytes. In addition, FGFs, also produced mainly by mature thymocytes and fibroblasts, are required for TECs and thymocytes proliferation to establish a complete and functional thymic microenvironment. Wnt signaling, expressed in TECs and fibroblasts, controls thymopoiesis and thymus size by regulating TECs and thymocyte and their progenitor proliferation. 
for the clinical application of "modification of thymus function" to improve our cellular immunity in physiological and pathological conditions such as transplantation, autoimmune diseases and aging.

\section{ACKNOWLEDGEMENTS}

The authors wish to thank Mr. Douglas Corley for his careful reading of the manuscript. This work was supported by grants from the National Basic Research Program (973 Program) (Nos. 2010CB945301, and 2011CB710903, Y.Z.), and National Natural Science Foundation of China (Grant Nos. C81072396 and U0832003, Y.Z.).

\section{ABBREVIATIONS}

APECED, autoimmune polyendocrinopathy; BMP, bone morphogenic protein; cTEC, cortical TEC; CTGF, connective tissue growth factor; DC, dendritic cell; DETC, dendritic epidermal T cell; FGF, fibroblast growth factor; FGFR2IIlb, FGF receptor R2-IIlb; FTOC, fetal thymic organ culture; LT $\beta R$, lymphotoxin $\beta$ receptor; LTi, lymphoid tissue inducer; NCC, neural crest cell; OPG, osteoprotegerin; RA, retinoic acid; RANK, receptor activator for NFKB; mTEC, medullary TEC; SCF, stem cell factor; TAK1, TGF- $\beta$ activating kinase 1 ; TEC, thymic epithelial cell; TNFR, tumor necrosis factor receptor; TRA, tissue-restricted antigen; UEA-1, Ulex europaeus agglutinin-1

\section{COMPLIANCE WITH ETHICS GUIDELINES}

Lina Sun, Haiying Luo, Hongran Li and Yong Zhao declare that we have no conflict of interest.

This article does not contain any studies with human or animal subjects performed by the authors.

\section{REFERENCES}

Akiyama, T., Maeda, S., Yamane, S., Ogino, K., Kasai, M., Kajiura, F., Matsumoto, M., and Inoue, J. (2005). Dependence of self-tolerance on TRAF6-directed development of thymic stroma. Science 308 , 248-251.

Akiyama, T., Shimo, Y., Yanai, H., Qin, J., Ohshima, D., Maruyama, Y., Asaumi, Y., Kitazawa, J., Takayanagi, H., Penninger, J.M., et al. (2008). The tumor necrosis factor family receptors RANK and CD40 cooperatively establish the thymic medullary microenvironment and self-tolerance. Immunity 29, 423-437.

Akiyama, T., Shinzawa, M., and Akiyama, N. (2012). TNF receptor family signaling in the development and functions of medullary thymic epithelial cells. Front Immunol 3, 278.

Alexandropoulos, K., and Danzl, N.M. (2012). Thymic epithelial cells: antigen presenting cells that regulate $\mathrm{T}$ cell repertoire and tolerance development. Immunol Res 54, 177-190.

Alexandropoulos, K., Donlin, L.T., Xing, L., and Regelmann, A.G. (2003). Sin: good or bad? A T lymphocyte perspective. Immunol Rev 192, 181-195.

Alpdogan, O., Hubbard, V.M., Smith, O.M., Patel, N., Lu, S., Goldberg, G.L., Gray, D.H., Feinman, J., Kochman, A.A., Eng, J.M., et al. (2006). Keratinocyte growth factor (KGF) is required for postnatal thymic regeneration. Blood 107, 2453-2460.

Anderson, G., and Takahama, Y. (2012). Thymic epithelial cells: working class heroes for $\mathrm{T}$ cell development and repertoire selection.
Trends Immunol 33, 256-263.

Anderson, M.S., Venanzi, E.S., Klein, L., Chen, Z., Berzins, S.P., Turley, S.J., von Boehmer, H., Bronson, R., Dierich, A., Benoist, C., et al. (2002). Projection of an immunological self shadow within the thymus by the aire protein. Science 298, 1395-1401.

Auerbach, R. (1960). Morphogenetic interactions in the development of the mouse thymus gland. Dev Biol 2, 271-284.

Balciunaite, G., Keller, M.P., Balciunaite, E., Piali, L., Zuklys, S., Mathieu, Y.D., Gill, J., Boyd, R., Sussman, D.J., and Hollander, G.A. (2002). Wnt glycoproteins regulate the expression of FoxN1, the gene defective in nude mice. Nat Immunol 3, 1102-1108.

Basak, S., and Hoffmann, A. (2008). Crosstalk via the NF-kappaB signaling system. Cytokine Growth Factor Rev 19, 187-197.

Baxter, R.M., and Brissette, J.L. (2002). Role of the nude gene in epithelial terminal differentiation. J Invest Dermatol 118, 303-309.

Bennett, A.R., Farley, A., Blair, N.F., Gordon, J., Sharp, L., and Blackburn, C.C. (2002). Identification and characterization of thymic epithelial progenitor cells. Immunity 16, 803-814.

Berent-Maoz, B., Montecino-Rodriguez, E., Signer, R.A., and Dorshkind, K. (2012). Fibroblast growth factor-7 partially reverses murine thymocyte progenitor aging by repression of Ink4a. Blood 119, 5715-5721.

Blackburn, C.C., Augustine, C.L., Li, R., Harvey, R.P., Malin, M.A., Boyd, R.L., Miller, J.F., and Morahan, G. (1996). The nu gene acts cell-autonomously and is required for differentiation of thymic epithelial progenitors. Proc Natl Acad Sci U S A 93, 5742-5746.

Bleul, C.C., and Boehm, T. (2005). BMP signaling is required for normal thymus development. J Immunol 175, 5213-5221.

Bleul, C.C., Corbeaux, T., Reuter, A., Fisch, P., Monting, J.S., and Boehm, T. (2006). Formation of a functional thymus initiated by a postnatal epithelial progenitor cell. Nature 441, 992-996.

Bockman, D.E., and Kirby, M.L. (1984). Dependence of thymus development on derivatives of the neural crest. Science 223, 498-500.

Boehm, T., Scheu, S., Pfeffer, K., and Bleul, C.C. (2003). Thymic medullary epithelial cell differentiation, thymocyte emigration, and the control of autoimmunity require lympho-epithelial cross talk via LTbetaR. J Exp Med 198, 757-769.

Bravo-Nuevo, A., O'Donnell, R., Rosendahl, A., Chung, J.H., Benjamin, L.E., and Odaka, C. RhoB deficiency in thymic medullary epithelium leads to early thymic atrophy. Int Immunol 23, 593-600.

Burkly, L., Hession, C., Ogata, L., Reilly, C., Marconi, L.A., Olson, D., Tizard, R., Cate, R., and Lo, D. (1995). Expression of relB is required for the development of thymic medulla and dendritic cells. Nature 373, 531-536.

Calderon, L., and Boehm, T. (2012). Synergistic, context-dependent, and hierarchical functions of epithelial components in thymic microenvironments. Cell 149, 159-172.

Candi, E., Dinsdale, D., Rufini, A., Salomoni, P., Knight, R.A., Mueller, M., Krammer, P.H., and Melino, G. (2007a). TAp63 and DeltaNp63 in cancer and epidermal development. Cell Cycle 6, 274-285.

Candi, E., Rufini, A., Terrinoni, A., Giamboi-Miraglia, A., Lena, A.M., Mantovani, R., Knight, R., and Melino, G. (2007b). DeltaNp63 regulates thymic development through enhanced expression of FgfR2 and Jag2. Proc Natl Acad Sci U S A 104, 11999-12004.

Chen, L., Xiao, S., and Manley, N.R. (2009). Foxn1 is required to maintain the postnatal thymic microenvironment in a dosage-sensitive manner. Blood 113, 567-574. 
Cheng, L., Guo, J., Sun, L., Fu, J., Barnes, P.F., Metzger, D., Chambon, P., Oshima, R.G., Amagai, T., and Su, D.M. (2010). Postnatal tissue-specific disruption of transcription factor FoxN1 triggers acute thymic atrophy. J Biol Chem 285, 5836-5847.

Chin, R.K., Lo, J.C., Kim, O., Blink, S.E., Christiansen, P.A., Peterson, P., Wang, Y., Ware, C., and Fu, Y.X. (2003). Lymphotoxin pathway directs thymic Aire expression. Nat Immunol 4, 1121-1127.

Chin, R.K., Zhu, M., Christiansen, P.A., Liu, W., Ware, C., Peltonen, L., Zhang, X., Guo, L., Han, S., Zheng, B., et al. (2006). Lymphotoxin pathway-directed, autoimmune regulator-independent central tolerance to arthritogenic collagen. J Immunol 177, 290-297.

Corbeaux, T., Hess, I., Swann, J.B., Kanzler, B., Haas-Assenbaum, A., and Boehm, T. (2010). Thymopoiesis in mice depends on a Foxn1positive thymic epithelial cell lineage. Proc Natl Acad Sci U S A 107, 16613-16618.

Cordier, A.C., and Heremans, J.F. (1975). Nude mouse embryo: ectodermal nature of the primordial thymic defect. Scand J Immunol 4, 193-196.

Danso-Abeam, D., Humblet-Baron, S., Dooley, J., and Liston, A. (2011). Models of aire-dependent gene regulation for thymic negative selection. Front Immunol 2, 14.

Danzl, N.M., Donlin, L.T., and Alexandropoulos, K. (2010). Regulation of medullary thymic epithelial cell differentiation and function by the signaling protein Sin. J Exp Med 207, 999-1013.

Derbinski, J., Gabler, J., Brors, B., Tierling, S., Jonnakuty, S., Hergenhahn, M., Peltonen, L., Walter, J., and Kyewski, B. (2005). Promiscuous gene expression in thymic epithelial cells is regulated at multiple levels. J Exp Med 202, 33-45.

Derbinski, J., Pinto, S., Rosch, S., Hexel, K., and Kyewski, B. (2008). Promiscuous gene expression patterns in single medullary thymic epithelial cells argue for a stochastic mechanism. Proc Natl Acad Sci U S A 105, 657-662.

Dooley, J., Erickson, M., and Farr, A.G. (2008). Alterations of the medullary epithelial compartment in the Aire-deficient thymus: implications for programs of thymic epithelial differentiation. J Immunol 181, 5225-5232.

Endres, R., Alimzhanov, M.B., Plitz, T., Futterer, A., Kosco-Vilbois, M.H., Nedospasov, S.A., Rajewsky, K., and Pfeffer, K. (1999). Mature follicular dendritic cell networks depend on expression of lymphotoxin beta receptor by radioresistant stromal cells and of lymphotoxin beta and tumor necrosis factor by B cells. J Exp Med 189, 159-168.

Erickson, M., Morkowski, S., Lehar, S., Gillard, G., Beers, C., Dooley, J., Rubin, J.S., Rudensky, A., and Farr, A.G. (2002). Regulation of thymic epithelium by keratinocyte growth factor. Blood 100, 3269-3278.

Farr, A.G., Dooley, J.L., and Erickson, M. (2002). Organization of thymic medullary epithelial heterogeneity: implications for mechanisms of epithelial differentiation. Immunol Rev 189, 20-27.

Flomerfelt, F.A., El Kassar, N., Gurunathan, C., Chua, K.S., League, S.C., Schmitz, S., Gershon, T.R., Kapoor, V., Yan, X.Y., Schwartz, R.H., et al. (2010). Tbata modulates thymic stromal cell proliferation and thymus function. J Exp Med 207, 2521-2532.

Flomerfelt, F.A., Kim, M.G., and Schwartz, R.H. (2000). Spatial, a gene expressed in thymic stromal cells, depends on three-dimensional thymus organization for its expression. Genes Immun 1, 391-401.

Frank, D.U., Fotheringham, L.K., Brewer, J.A., Muglia, L.J., Tristani-Firouzi, M., Capecchi, M.R., and Moon, A.M. (2002). An Fgf8 mouse mutant phenocopies human 22q11 deletion syndrome. Develop- ment 129, 4591-4603.

Futterer, A., Mink, K., Luz, A., Kosco-Vilbois, M.H., and Pfeffer, K. (1998). The lymphotoxin beta receptor controls organogenesis and affinity maturation in peripheral lymphoid tissues. Immunity 9 , 59-70.

Gabler, J., Arnold, J., and Kyewski, B. (2007). Promiscuous gene expression and the developmental dynamics of medullary thymic epithelial cells. Eur J Immunol 37, 3363-3372.

Gardiner, J.R., Jackson, A.L., Gordon, J., Lickert, H., Manley, N.R., and Basson, M.A. (2012). Localised inhibition of FGF signalling in the third pharyngeal pouch is required for normal thymus and parathyroid organogenesis. Development 139, 3456-3466.

Gardner, J.M., Fletcher, A.L., Anderson, M.S., and Turley, S.J. (2009). AIRE in the thymus and beyond. Curr Opin Immunol 21, 582-589.

Gillard, G.O., Dooley, J., Erickson, M., Peltonen, L., and Farr, A.G. (2007). Aire-dependent alterations in medullary thymic epithelium indicate a role for Aire in thymic epithelial differentiation. $\mathrm{J}$ Immunol 178, 3007-3015.

Gillard, G.O., and Farr, A.G. (2005). Contrasting models of promiscuous gene expression by thymic epithelium. J Exp Med 202, 15-19.

Giraud, M., Yoshida, H., Abramson, J., Rahl, P.B., Young, R.A., Mathis, D., and Benoist, C. (2012). Aire unleashes stalled RNA polymerase to induce ectopic gene expression in thymic epithelial cells. Proc Natl Acad Sci U S A 109, 535-540.

Gommeaux, J., Gregoire, C., Nguessan, P., Richelme, M., Malissen, M., Guerder, S., Malissen, B., and Carrier, A. (2009). Thymus-specific serine protease regulates positive selection of a subset of CD4+ thymocytes. Eur J Immunol 39, 956-964.

Gossens, K., Naus, S., Hollander, G.A., and Ziltener, H.J. (2010). Deficiency of the metalloproteinase-disintegrin ADAM8 is associated with thymic hyper-cellularity. PLoS One 5, e12766.

Gravano, D.M., McLelland, B.T., Horiuchi, K., and Manilay, J.O. (2010). ADAM17 deletion in thymic epithelial cells alters aire expression without affecting $\mathrm{T}$ cell developmental progression. PLoS One 5, e13528.

Gray, D., Abramson, J., Benoist, C., and Mathis, D. (2007). Proliferative arrest and rapid turnover of thymic epithelial cells expressing Aire. J Exp Med 204, 2521-2528.

Guerder, S., Viret, C., Luche, H., Ardouin, L., and Malissen, B. (2012). Differential processing of self-antigens by subsets of thymic stromal cells. Curr Opin Immunol 24, 99-104.

Guo, J., Feng, Y., Barnes, P., Huang, F.F., Idell, S., Su, D.M., and Shams, H. (2012). Deletion of FoxN1 in the thymic medullary epithelium reduces peripheral $\mathrm{T}$ cell responses to infection and mimics changes of aging. PLoS One 7, e34681.

Hale, L.P., and Markert, M.L. (2004). Corticosteroids regulate epithelial cell differentiation and Hassall body formation in the human thymus. J Immunol 172, 617-624.

Hamazaki, Y., Fujita, H., Kobayashi, T., Choi, Y., Scott, H.S., Matsumoto, M., and Minato, N. (2007). Medullary thymic epithelial cells expressing Aire represent a unique lineage derived from cells expressing claudin. Nat Immunol 8, 304-311.

Heinonen, K.M., Vanegas, J.R., Brochu, S., Shan, J., Vainio, S.J., and Perreault, C. (2011a). Wnt4 regulates thymic cellularity through the expansion of thymic epithelial cells and early thymic progenitors. Blood 118, 5163-5173.

Heinonen, K.M., Vanegas, J.R., Lew, D., Krosl, J., and Perreault, C. 
(2011b). Wnt4 enhances murine hematopoietic progenitor cell expansion through a planar cell polarity-like pathway. PLoS One 6, e19279.

Hikosaka, Y., Nitta, T., Ohigashi, I., Yano, K., Ishimaru, N., Hayashi, Y., Matsumoto, M., Matsuo, K., Penninger, J.M., Takayanagi, H., et al. (2008). The cytokine RANKL produced by positively selected thymocytes fosters medullary thymic epithelial cells that express autoimmune regulator. Immunity 29, 438-450.

Irla, M., Hollander, G., and Reith, W. (2009). Control of central selftolerance induction by autoreactive CD4+ thymocytes. Trends Immunol 31, 71-79.

Irla, M., Hugues, S., Gill, J., Nitta, T., Hikosaka, Y., Williams, I.R., Hubert, F.X., Scott, H.S., Takahama, Y., Hollander, G.A., et al. (2008). Autoantigen-specific interactions with CD4+ thymocytes control mature medullary thymic epithelial cell cellularity. Immunity 29 , 451-463.

Itoi, M., Kawamoto, H., Katsura, Y., and Amagai, T. (2001). Two distinct steps of immigration of hematopoietic progenitors into the early thymus anlage. Int Immunol 13, 1203-1211.

Janes, S.M., Ofstad, T.A., Campbell, D.H., Watt, F.M., and Prowse, D.M. (2004). Transient activation of FOXN1 in keratinocytes induces a transcriptional programme that promotes terminal differentiation: contrasting roles of FOXN1 and Akt. J Cell Sci 117, 4157-4168.

Jenkinson, W.E., Bacon, A., White, A.J., Anderson, G., and Jenkinson, E.J. (2008). An epithelial progenitor pool regulates thymus growth. $\mathrm{J}$ Immunol 181, 6101-6108.

Jenkinson, W.E., Jenkinson, E.J., and Anderson, G. (2003). Differential requirement for mesenchyme in the proliferation and maturation of thymic epithelial progenitors. J Exp Med 198, 325-332.

Kajiura, F., Sun, S., Nomura, T., Izumi, K., Ueno, T., Bando, Y., Kuroda, N., Han, H., Li, Y., Matsushima, A., et al. (2004). NF-kappa B-inducing kinase establishes self-tolerance in a thymic stroma-dependent manner. J Immunol 172, 2067-2075.

Kinoshita, D., Hirota, F., Kaisho, T., Kasai, M., Izumi, K., Bando, Y., Mouri, Y., Matsushima, A., Niki, S., Han, H., et al. (2006). Essential role of IkappaB kinase alpha in thymic organogenesis required for the establishment of self-tolerance. J Immunol 176, 3995-4002.

Koch, U., Fiorini, E., Benedito, R., Besseyrias, V., Schuster-Gossler, K., Pierres, M., Manley, N.R., Duarte, A., Macdonald, H.R., and Radtke, F. (2008). Delta-like 4 is the essential, nonredundant ligand for Notch1 during thymic T cell lineage commitment. J Exp Med 205, 2515-2523.

Kvell, K., Varecza, Z., Bartis, D., Hesse, S., Parnell, S., Anderson, G., Jenkinson, E.J., and Pongracz, J.E. (2010). Wnt4 and LAP2alpha as pacemakers of thymic epithelial senescence. PLoS One 5, e10701.

Liiv, I., Haljasorg, U., Kisand, K., Maslovskaja, J., Laan, M., and Peterson, P. (2012). AIRE-induced apoptosis is associated with nuclear translocation of stress sensor protein GAPDH. Biochem Biophys Res Commun 423, 32-37.

Liu, C., Saito, F., Liu, Z., Lei, Y., Uehara, S., Love, P., Lipp, M., Kondo, S., Manley, N., and Takahama, Y. (2006). Coordination between CCR7- and CCR9-mediated chemokine signals in prevascular fetal thymus colonization. Blood 108, 2531-2539.

Lomada, D., Liu, B., Coghlan, L., Hu, Y., and Richie, E.R. (2007). Thymus medulla formation and central tolerance are restored in IKKalpha-/- mice that express an IKKalpha transgene in keratin 5+ thymic epithelial cells. J Immunol 178, 829-837.

Macedo, C., Evangelista, A.F., Marques, M.M., Octacilio-Silva, S., Donadi, E.A., Sakamoto-Hojo, E.T., and Passos, G.A. (2012). Autoimmune regulator (Aire) controls the expression of microRNAs in medullary thymic epithelial cells. Immunobiology 218, 554-560.

Manley, N.R., and Condie, B.G. (2010). Transcriptional regulation of thymus organogenesis and thymic epithelial cell differentiation. Prog Mol Biol TransI Sci 92, 103-120.

Martins, V.C., Boehm, T., and Bleul, C.C. (2008). Ltbetar signaling does not regulate Aire-dependent transcripts in medullary thymic epithelial cells. J Immunol 181, 400-407.

Masuda, K., Germeraad, W.T., Satoh, R., Itoi, M., Ikawa, T., Minato, N., Katsura, Y., van Ewijk, W., and Kawamoto, H. (2009). Notch activation in thymic epithelial cells induces development of thymic microenvironments. Mol Immunol 46, 1756-1767.

Mathis, D., and Benoist, C. (2009). Aire. Annu Rev Immunol 27, 287312.

Min, D., Panoskaltsis-Mortari, A., Kuro, O.M., Hollander, G.A., Blazar, B.R., and Weinberg, K.I. (2007). Sustained thymopoiesis and improvement in functional immunity induced by exogenous KGF administration in murine models of aging. Blood 109, 2529-2537.

Min, D., Taylor, P.A., Panoskaltsis-Mortari, A., Chung, B., Danilenko, D.M., Farrell, C., Lacey, D.L., Blazar, B.R., and Weinberg, K.I. (2002). Protection from thymic epithelial cell injury by keratinocyte growth factor: a new approach to improve thymic and peripheral T-cell reconstitution after bone marrow transplantation. Blood 99, 4592-4600

Mori, K., Itoi, M., Tsukamoto, N., and Amagai, T. (2010). Foxn1 is essential for vascularization of the murine thymus anlage. Cell Immunol 260, 66-69.

Mouri, Y., Yano, M., Shinzawa, M., Shimo, Y., Hirota, F., Nishikawa, Y., Nii, T., Kiyonari, H., Abe, T., Uehara, H., et al. (2011). Lymphotoxin signal promotes thymic organogenesis by eliciting RANK expression in the embryonic thymic stroma. J Immunol 186, 5047-5057.

Murata, S., Sasaki, K., Kishimoto, T., Niwa, S., Hayashi, H., Takahama, Y., and Tanaka, K. (2007). Regulation of CD8+ T cell development by thymus-specific proteasomes. Science 316, 1349-1353.

Murata, S., Takahama, Y., and Tanaka, K. (2008). Thymoproteasome: probable role in generating positively selecting peptides. Curr Opin Immunol 20, 192-196.

Nakagawa, T., Roth, W., Wong, P., Nelson, A., Farr, A., Deussing, J., Villadangos, J.A., Ploegh, H., Peters, C., and Rudensky, A.Y. (1998). Cathepsin L: critical role in li degradation and CD4 T cell selection in the thymus. Science 280, 450-453.

Nehls, M., Pfeifer, D., Schorpp, M., Hedrich, H., and Boehm, T. (1994). New member of the winged-helix protein family disrupted in mouse and rat nude mutations. Nature 372, 103-107.

Nishikawa, Y., Hirota, F., Yano, M., Kitajima, H., Miyazaki, J., Kawamoto, H., Mouri, Y., and Matsumoto, M. (2009). Biphasic Aire expression in early embryos and in medullary thymic epithelial cells before end-stage terminal differentiation. J Exp Med 207, 963-971.

Nowell, C.S., Bredenkamp, N., Tetelin, S., Jin, X., Tischner, C., Vaidya, H., Sheridan, J.M., Stenhouse, F.H., Heussen, R., Smith, A.J., et al. (2011). Foxn1 regulates lineage progression in cortical and medullary thymic epithelial cells but is dispensable for medullary sublineage divergence. PLoS Genet 7, e1002348.

Oliveira, E.H., Macedo, C., Donate, P.B., Almeida, R.S., Pezzi, N., 
Nguyen, C., Rossi, M.A., Sakamoto-Hojo, E.T., Donadi, E.A., and Passos, G.A. (2012). Expression profile of peripheral tissue antigen genes in medullary thymic epithelial cells (mTECs) is dependent on mRNA levels of autoimmune regulator (Aire). Immunobiology 218 , 96-104.

Osada, M., Jardine, L., Misir, R., Andl, T., Millar, S.E., and Pezzano, M. (2010). DKK1 mediated inhibition of Wnt signaling in postnatal mice leads to loss of TEC progenitors and thymic degeneration. PLoS One 5, e9062.

Patel, S.R., Gordon, J., Mahbub, F., Blackburn, C.C., and Manley, N.R. (2006). Bmp4 and Noggin expression during early thymus and parathyroid organogenesis. Gene Expr Patterns 6, 794-799.

Ramsey, C., Winqvist, O., Puhakka, L., Halonen, M., Moro, A., Kampe, O., Eskelin, P., Pelto-Huikko, M., and Peltonen, L. (2002). Aire deficient mice develop multiple features of APECED phenotype and show altered immune response. Hum Mol Genet 11, 397-409.

Revest, J.M., Suniara, R.K., Kerr, K., Owen, J.J., and Dickson, C. (2001). Development of the thymus requires signaling through the fibroblast growth factor receptor R2-IIIb. J Immunol 167, 19541961.

Ripen, A.M., Nitta, T., Murata, S., Tanaka, K., and Takahama, Y. (2011). Ontogeny of thymic cortical epithelial cells expressing the thymoproteasome subunit beta5t. Eur J Immunol 41, 1278-1287.

Roberts, N.A., White, A.J., Jenkinson, W.E., Turchinovich, G., Nakamura, K., Withers, D.R., McConnell, F.M., Desanti, G.E., Benezech, C., Parnell, S.M., et al. (2012). Rank signaling links the development of invariant gammadelta T cell progenitors and Aire(+) medullary epithelium. Immunity 36, 427-437.

Rode, I., and Boehm, T. (2012). Regenerative capacity of adult cortical thymic epithelial cells. Proc Natl Acad Sci U S A 109, 3463-3468.

Rodewald, H.R., Paul, S., Haller, C., Bluethmann, H., and Blum, C. (2001). Thymus medulla consisting of epithelial islets each derived from a single progenitor. Nature 414, 763-768.

Rossi, S., Blazar, B.R., Farrell, C.L., Danilenko, D.M., Lacey, D.L., Weinberg, K.I., Krenger, W., and Hollander, G.A. (2002). Keratinocyte growth factor preserves normal thymopoiesis and thymic microenvironment during experimental graft-versus-host disease. Blood 100, 682-691.

Rossi, S.W., Jeker, L.T., Ueno, T., Kuse, S., Keller, M.P., Zuklys, S., Gudkov, A.V., Takahama, Y., Krenger, W., Blazar, B.R., et al. (2007a). Keratinocyte growth factor (KGF) enhances postnatal Tcell development via enhancements in proliferation and function of thymic epithelial cells. Blood 109, 3803-3811.

Rossi, S.W., Jenkinson, W.E., Anderson, G., and Jenkinson, E.J. (2006). Clonal analysis reveals a common progenitor for thymic cortical and medullary epithelium. Nature 441, 988-991.

Rossi, S.W., Kim, M.Y., Leibbrandt, A., Parnell, S.M., Jenkinson, W.E., Glanville, S.H., McConnell, F.M., Scott, H.S., Penninger, J.M., Jenkinson, E.J., et al. (2007b). RANK signals from CD4(+)3(-) inducer cells regulate development of Aire-expressing epithelial cells in the thymic medulla. J Exp Med 204, 1267-1272.

Saade, M., Irla, M., Yammine, M., Boulanger, N., Victorero, G., Vincentelli, R., Penninger, J.M., Hollander, G.A., Chauvet, S., and Nguyen, C. (2010). Spatial (Tbata) expression in mature medullary thymic epithelial cells. Eur J Immunol 40, 530-538.

Seach, N., Ueno, T., Fletcher, A.L., Lowen, T., Mattesich, M., Engwerda, C.R., Scott, H.S., Ware, C.F., Chidgey, A.P., Gray, D.H., et al.
(2008). The lymphotoxin pathway regulates Aire-independent expression of ectopic genes and chemokines in thymic stromal cells. J Immunol 180, 5384-5392.

Senoo, M., Pinto, F., Crum, C.P., and McKeon, F. (2007). p63 Is essential for the proliferative potential of stem cells in stratified epithelia. Cell 129, 523-536.

Shakib, S., Desanti, G.E., Jenkinson, W.E., Parnell, S.M., Jenkinson, E.J., and Anderson, G. (2009). Checkpoints in the development of thymic cortical epithelial cells. J Immunol 182, 130-137.

Sitnik, K.M., Kotarsky, K., White, A.J., Jenkinson, W.E., Anderson, G., and Agace, W.W. (2012). Mesenchymal cells regulate retinoic acid receptor-dependent cortical thymic epithelial cell homeostasis. J Immunol 188, 4801-4809.

Su, D., Ellis, S., Napier, A., Lee, K., and Manley, N.R. (2001). Hoxa3 and pax 1 regulate epithelial cell death and proliferation during thymus and parathyroid organogenesis. Dev Biol 236, 316-329.

Su, D.M., Navarre, S., Oh, W.J., Condie, B.G., and Manley, N.R. (2003). A domain of Foxn1 required for crosstalk-dependent thymic epithelial cell differentiation. Nat Immunol 4, 1128-1135.

Suniara, R.K., Jenkinson, E.J., and Owen, J.J. (2000). An essential role for thymic mesenchyme in early $\mathrm{T}$ cell development. $\mathrm{J}$ Exp Med 191, 1051-1056.

Takahama, Y., Takada, K., Murata, S., and Tanaka, K. (2012). beta5tcontaining thymoproteasome: specific expression in thymic cortical epithelial cells and role in positive selection of CD8+ T cells. Curr Opin Immunol 24, 92-98.

Talaber, G., Kvell, K., Varecza, Z., Boldizsar, F., Parnell, S.M., Jenkinson, E.J., Anderson, G., Berki, T., and Pongracz, J.E. (2011). Wnt4 protects thymic epithelial cells against dexamethasone-induced senescence. Rejuvenation Res 14, 241-248.

Tsai, P.T., Lee, R.A., and Wu, H. (2003). BMP4 acts upstream of FGF in modulating thymic stroma and regulating thymopoiesis. Blood 102, 3947-3953.

Varecza, Z., Kvell, K., Talaber, G., Miskei, G., Csongei, V., Bartis, D., Anderson, G., Jenkinson, E.J., and Pongracz, J.E. (2011). Multiple suppression pathways of canonical Wnt signalling control thymic epithelial senescence. Mech Ageing Dev 132, 249-256.

Venanzi, E.S., Gray, D.H., Benoist, C., and Mathis, D. (2007). Lymphotoxin pathway and Aire influences on thymic medullary epithelial cells are unconnected. J Immunol 179, 5693-5700.

Viret, C., Leung-Theung-Long, S., Serre, L., Lamare, C., Vignali, D.A., Malissen, B., Carrier, A., and Guerder, S. (2011). Thymus-specific serine protease controls autoreactive CD4 T cell development and autoimmune diabetes in mice. J Clin Invest 121, 1810-1821.

Wang, X., Laan, M., Bichele, R., Kisand, K., Scott, H.S., and Peterson, P. (2012). Post-Aire maturation of thymic medullary epithelial cells involves selective expression of keratinocyte-specific autoantigens. Front Immunol 3, 19.

Weber, S., Niessen, M.T., Prox, J., Lullmann-Rauch, R., Schmitz, A., Schwanbeck, R., Blobel, C.P., Jorissen, E., de Strooper, B., Niessen, C.M., et al. (2011). The disintegrin/metalloproteinase Adam10 is essential for epidermal integrity and Notch-mediated signaling. Development 138, 495-505.

Weih, F., Carrasco, D., Durham, S.K., Barton, D.S., Rizzo, C.A., Ryseck, R.P., Lira, S.A., and Bravo, R. (1995). Multiorgan inflammation and hematopoietic abnormalities in mice with a targeted disruption of RelB, a member of the NF-kappa B/Rel family. Cell 80, 
331-340.

Wendling, O., Dennefeld, C., Chambon, P., and Mark, M. (2000). Retinoid signaling is essential for patterning the endoderm of the third and fourth pharyngeal arches. Development 127, 1553-1562.

West, K.P., Jr., Howard, G.R., and Sommer, A. (1989). Vitamin A and infection: public health implications. Annu Rev Nutr 9, 63-86.

White, A.J., Nakamura, K., Jenkinson, W.E., Saini, M., Sinclair, C., Seddon, B., Narendran, P., Pfeffer, K., Nitta, T., Takahama, Y., et al. (2010). Lymphotoxin signals from positively selected thymocytes regulate the terminal differentiation of medullary thymic epithelial cells. J Immunol 185, 4769-4776.

Wodarz, A., and Nusse, R. (1998). Mechanisms of Wnt signaling in development. Annu Rev Cell Dev Biol 14, 59-88.

Xia, J., Wang, H., Guo, J., Zhang, Z., Coder, B., and Su, D.M. (2012). Age-related disruption of steady-state thymic medulla provokes autoimmune phenotype via perturbing negative selection. Aging Dis 3 , 248-259.

Yano, M., Kuroda, N., Han, H., Meguro-Horike, M., Nishikawa, Y., Kiyonari, H., Maemura, K., Yanagawa, Y., Obata, K., Takahashi, S., et al. (2008). Aire controls the differentiation program of thymic epithelial cells in the medulla for the establishment of self-tolerance. J Exp Med 205, 2827-2838.

Zhang, B., Wang, Z., Ding, J., Peterson, P., Gunning, W.T., and Ding,
H.F. (2006). NF-kappaB2 is required for the control of autoimmunity by regulating the development of medullary thymic epithelial cells. $J$ Biol Chem 281, 38617-38624.

Zhang, L., Sun, L., and Zhao, Y. (2007). Thymic epithelial progenitor cells and thymus regeneration: an update. Cell Res 17, 50-55.

Zhu, M., Brown, N.K., and Fu, Y.X. (2010). Direct and indirect roles of the LTbetaR pathway in central tolerance induction. Trends Immunol 31, 325-331.

Zhu, M., Chin, R.K., Christiansen, P.A., Lo, J.C., Liu, X., Ware, C., Siebenlist, U., and Fu, Y.X. (2006). NF-kappaB2 is required for the establishment of central tolerance through an Aire-dependent pathway. J Clin Invest 116, 2964-2971.

Zhu, M., and Fu, Y. (2010). The complicated role of NF-kappaB in T-cell selection. Cell Mol Immunol 7, 89-93.

Zook, E.C., Krishack, P.A., Zhang, S., Zeleznik-Le, N.J., Firulli, A.B., Witte, P.L., and Le, P.T. (2011). Overexpression of Foxn1 attenuates age-associated thymic involution and prevents the expansion of peripheral CD4 memory T cells. Blood 118, 5723-5731.

Zuklys, S., Mayer, C.E., Zhanybekova, S., Stefanski, H.E., Nusspaumer, G., Gill, J., Barthlott, T., Chappaz, S., Nitta, T., Dooley, J., et al. (2012). MicroRNAs control the maintenance of thymic epithelia and their competence for $\mathrm{T}$ lineage commitment and thymocyte selection. J Immunol 189, 3894-3904. 